\title{
ODONTOMA COMPOSTO - RELATO DE CASO
}

Felipe Garcia de MATOS, Eduardo MORESCHI, Carlos Juliano SOCOLOSKI, Pedro Henrique NEIRO, Rodrigo de Andrade VINCENZI

Refere-se a um hamartoma odontogênico com alto grau de diferenciação celular. Sua etiologia envolve distúrbios de desenvolvimento de origem embrionária, podendo estar associada a traumatismos e infecções. Embora o crescimento seja lento, na maioria dos casos são assintomáticos, geralmente causam retenções e rechaçamentos dentais, e devido à expansão da maxila, complicações de ordem funcional e estética podem ocorrer. Os odontomas são classificados em composto e complexo. Os compostos ocorrem com maior freqüência na região anterior da maxila, enquanto que os complexos são encontrados em ambos maxilares, principalmente na região de molares. Nos aspectos radiográficos dessa lesão apresentam estruturas radiopacas, semelhantes a pequenos dentes rodeadas por uma linha radiolúcida. Já nos aspectos microscópicos constitui-se de estruturas calcificadas semelhantes a dentes e uma cápsula fibrosa compatível com saco dentário. $O$ tratamento indicado envolve a remoção cirúrgica conservadora. O prognóstico é excelente. Paciente do gênero masculino, leucoderma, 20 anos de idade, profissão soldador, compareceu ao projeto de lesões bucais do Centro Universitário de Maringá - CESUMAR por indicação ortodôntica. Ao exame clínico observou-se a ausência do elemento 13, ausência de sintomatologia dolorosa. Já ao exame radiográfico foi constatado uma massa calcificada, características de pequenos dentes, delimitada por um halo radiolúcido localizado na região entre os elementos 11 e 21, e elemento 13 retido. Após a remoção da lesão e processamento histotécnico o diagnóstico foi compatível com odontoma composto.

Palavras-chave: Odontoma; Composto; Hamartoma. 